\title{
How COVID has Illuminated the Pitfalls of a Single-Payer System in the US
}

Tamela J. White, BSN, MPH, JD' ${ }^{1}$ Nicholas Wright, JD²

Health care quality measures are impacted by resources invested into outarticle.

comes. COVID-19 has had a direct impact on quality outcomes, the same illuminating just some of the problems with the concept of a single-payer health care system. The US government's inefficiencies in attempting to run the single-payer system known as IHS in context with its repeated failures in managing the COVID-19 crises along with the economic impact of the same is but one call for strong leadership to dispel the myth that a single-payer system is a panacea for America.

Correspondence to: Tamela J. White Farrell, White \& Legg tjw@farrell3.com

\section{KEYWORDS}

COVID, Single-Payer, Outcomes, Quality

Peering through the looking glass of COVID-19 (COVID), we have now all seen the dark corners that have suddenly illuminated the fallibility of a qualityoriented single care health system in America. COVID has exponentially exposed an already fragile health care system whose margins are so thin that rural and even metropolitan-based hospitals struggle for survival and many are on life support. The government's ineffectiveness in handling a health crisis is making history as this pandemic continues. It is simply a fantasy to believe that a magical cure would be effectuated if the government became the hub of the entire health care economy via a single-payer system. Two intersecting subjects are discussed in this editorial. First, there already exists a single-payer system in the US - the Indian Health Service (IHS). Its quality measures and preliminary COVID experience is illustrative of the failures of a single-payer proposal particularly in rural economies. Second, the economic hemorrhage experienced secondary to COVID provides compelling proof that a single-payer model is not the answer.

As the result of a treaty with the United States government, the American Indians and the Alaskan
Natives have treaty rights to federal health care services through the Department of Health and Human Services ${ }^{1}$, executed by the Indian Health Service (IHS). 2 The IHS purportedly provides "comprehensive health service" to the 573 federally recognized tribal communities all of which are rural. ${ }^{2}$ The healthcare provided is severely lacking in quality outcomes due to underfunding. ${ }^{3}$ For instance, American Indians and Alaskan Natives lag behind all race populations in life expectancy by 4.4 years. ${ }^{3}$

The deficiencies in the Native American Healthcare system have never been more pronounced as in the wake of the COVID pandemic. Like they did with tuberculosis, diabetes, and cardiovascular disease, Native Americans are suffering from COVID at a disproportionally higher rate than the rest of the country. ${ }^{4}$ The Navajo Nation, if a state, would have the fifth-highest COVID death rate in the US. ${ }^{5}$ The National Congress of American Indians has stated that the Native American hospitals are simply too overcrowded and that their facilities and equipment are outdated; those facilities and equipment are 
dependent upon a single-payer and not market forces. ${ }^{5}$ This failing infrastructure was evident among the Oglala Sioux in South Dakota where there were only twenty-four COVID tests, six ventilators, and four beds on hand for the 50,000 members of the tribe. ${ }^{6}$

Taking this experience and considering it on a more macro-scale, COVID has exposed the Achilles of a single-payer system by the consequences of the necessity to stop elective, non-urgent/non-emergent and preventative care throughout the health care system. Would the US health care system move to a model of government-run and managed IHS programs, the catastrophic further erosion of health care quality would become the measurable outcome.

Due to COVID, there has been a necessary shift to a single focus - the pandemic. With the loss of the diversified menu of healthcare offerings, such as elective procedures, countless health care systems have furloughed workers.? A Kentucky medical center, St. Claire HealthCare, had to furlough 25\% of its workforce due to a lack of patients. ${ }^{8}$ A Mainebased primary care facility cited the stoppage of non-essential procedures as its reason for furloughing one-third of its workforce. ${ }^{8}$ As COVID has dragged on, more hospitals face harder financial times. A Kaufman Hall report cited the cancellation of elective procedures as the main contributor to a $13 \%$ revenue reduction comparing March of 2020 to March of 2019, with losses expected to become greater as those services which offset costs of intensive care and emergency medicine are closed.9 The American Hospital Association estimates that COVID could cost hospitals $\$ 200$ billion from March 1 to June 30, 2020, alone. The biggest loss by far comes from canceled elective procedures with a price tag of $\$ 161.4$ billion dollars.

What do the pandemic, the IHS data, and these economic projections then forecast for the consequences to rural hospitals under a singlepayer system? First, due to COVID, there has been a direct impact upon the country's GDP; health care's contribution shows at least an $18 \%$ reduction in consumer healthcare spending 10 with reduced health care spending a key factor in GDP suffering the greatest loss since the Great Depression. Under a proposed single-payer system, reimbursements at the government-specified, price-fixed rate, would eliminate all opportunity for health-care monetary reinvestment. In a recent Navigant study, a hypothetical medium-sized nonprofit hospital would experience a $\$ 330$ million decrease in revenue and negative margins of $22 \%$ under such a system. ${ }^{11}$ Even if the single-payer system paid out $120 \%$ of the current Medicaid rates, this fictional hospital would have experienced a loss of $\$ 158$ million annually.

One response to an argument against a single-payer system is that the government could set a rate that works. For example, with the Navigant analysis, some have argued that if $120 \%$ of Medicare rates are not sufficient, then the government could simply set the rates to $140 \%$ of Medicare rates. The problem, outside the obvious astronomical cost and lack of financial security of such a plan, can be seen by the current state of the IHS and Native American health outcomes. The IHS, operated by the national government, is supposed to provide comprehensive health coverage to federally recognized Native American tribes. Yet, these tribes find themselves with a critically underfunded and neglected health system just like the many intensive care units without ventilators and masks.

Quality outcomes need resources. The inability to provide masks and ventilators alone is proof. To bend the curve on health literacy, self-responsibility in health management, disease detection and prevention, and overall life quality and life expectancy outcomes, investment of capital, both human and monetary, is key. The IHS system is without competition. COVID has prevented competition. Competition and capitalism are not bad words in the context of healthcare. They are key components that need strong leadership and management to move our systems forward, not backward.

One last example brings this point home. In Nicholas County West Virginia, the cost per capita for an inpatient hospital stay is $\$ 2,021.80 . .^{12}$ How is this cost per capita, cost of healthcare per person, spread out over the population of the county, getting paid? Look at how the county is insured: $92.3 \%$ of its population has health coverage, with $40.2 \%$ on employee plans, $23.9 \%$ on Medicaid, $17.5 \%$ on 
Medicare, $9.08 \%$ on non-group plans, and $1.66 \%$ on military or VA plans. ${ }^{13}$ If this hospital's costs are $\$ 100,000$, then under the current system the hospital receives $\$ 42,560$ from Medicare/Medicaid; $\$ 85,120$ from the non-Medicaid/Medicare group; and nothing from the uninsured thus receiving $\$ 127,680$ for incurred costs of $\$ 100,000$. Under a single-payer system at current Medicare/Medicaid rates, the hospital would receive $\$ 100,000$ and die. Other similar examples exist.

Policymakers need to move beyond the rhetoric and bend the curve forward. America's health care system needs a re-set but government takeover is not the answer.

\section{AUTHOR AFFILIATIONS}

1. Farrell, White \& LEgg, PLLC, Huntington, West Virginia

2. University of Kentucky College of Law, Lexington, Kentucky

\section{REFERENCES}

1. IHS. Basis for Health Services. [Internet]. Jan 2015 [cited 2020 July 30]. Available from: https://www.ihs.gov/newsroom/factsheets/ basisforhealthservices/

2. IHS. About IHS [Internet]. [cited 2020 July 30]. Available from: https://www.ihs.gov/aboutihs/

3. Smith M. Native Americans: a crisis in health equity. [Internet]. [cited 2020 July 30]. Available from: https://www.americanbar.org/groups/crsj/ publications/human_rights_magazine_home/ the-state-of-healthcare-in-the-united-states/ native-american-crisis-in-health-equity/

4. Hayes C, Mabie N, Santucci J. Native American tribes have been hit hard by coronavirus, and they're battling red tape to get help. [Internet]. 2020 May [cited 2020 July 30]. Available from: https://www.usatoday.com/story/news/ politics/2020/04/24/coronavirus-indian-countryhit-hard-tribes-battle-red-tape/5130415002/

5. Romero S, Healy J. Tribal nations face most severe crisis in decades as the coronavirus closes casinos. [Internet]. 2020 May 11 [updated 2020 May 13, cited 2020 July 30]. Available from https://www.nytimes.com/2020/05/11/us/ coronavirus-native-americans-indian-country. html

6. Nagle R. Native Americans being left out of US coronavirus data and labelled as 'other.' [Internet]. 2020 Apr 24 [cited 2020 July 30]. Available from: https://www.theguardian.com/us-news/2020/ apr/24/us-native-americans-left-out-coronavirusdata

7. Advisory Board. Covid-19 could carry a $\$ 200 B$ price tag for hospitals. [Internet]. 2020 May 7 [cited 2020 July 30]. Available from: https://www. advisory.com/daily-briefing/2020/05/07/covidfinance

8. Respaut R, Spalding R. U.S. hospitals halt lucrative procedures amid coronavirus crisis, job cuts follow. [Internet]. 2020 Mar 21 [cited 2020 July 30]. Available from: https://www. reuters.com/article/us-health-coronavirususa-hospitals/u-s-hospitals-halt-lucrativeprocedures-amid-coronavirus-crisis-job-cutsfollow-idUSKBN211388

9. Blake J. National Hospital Flash Report Summary: April 2020 [Internet] 2020 [cited 2020 July 30]. Available from: https://www.kaufmanhall.com/ ideas-resources/article/covid-19-hits-hospitalshard-march?utm_source=mkto\&utm

10. Coombs B. Plunge in health-care spending a big reason US economy sank in first quarter. [Internet]. 2020 Apr 29 [cited 2020 July 30]. Available from: https://www.cnbc. com/2020/04/29/plunge-in-health-carespending-a-big-reason-us-economy-sank-in-firstquarter.html

11. Goldsmith J, Leibach J, Eicher K. Medicare expansion: a preliminary analysis of hospital financial impacts. [Internet]. 2020 Mar [cited 2020 July 30]. Available from: https:// americashealthcarefuture.org/wp-content/ uploads/2020/03/Navigant_MedicareExpansion-Hospitals.pdf

12. Agency of Healthcare Research and Quality. Statistics for community hospital stays 2015 West Virginia, by county or county equivalent [Internet]. [cited 2020 July 30]. Available from: https://hcupnet.ahrq.gov/\#query/ 